\title{
Amplitude of visual evoked potentials as a function of illuminance'
}

J. M. FUSTER AND G. SIERRA, BRAIN RESEARCH INSTITUTE, UNIVERSITY OF CALIFORNIA, LOS Angeles, Calif. 90024

Recording electrodes were implanted in the lateral geniculate body and striate cortex of rabbits and cats. Primary evoked responses to a brief light flash were recorded from the two locations in the unanesthetized animal. Both at geniculate and cortical levels a power function was found to express satisfactorily in the two species the relationship of response amplitude to illuminance, although a log function generally provided almost as good a fit for the data.

It has been shown that the transformation of energy impinging upon sensory organs into bioelectrical activity is accomplished in accordance with principles resembling those demonstrated in psychophysics. Thus, investigation on peripheral structures of the visual system has lent support to a neurophysiological parallel of Fechner's law by showing that the magnitude of the neural response to an optic stimulus varies as a function of the logarithm of stimulus intensity (Hartline \& Graham 1932; Granit 1955). In recent years, however, the adequacy of the Fechnerian logarithmic expression in psychophysics has been challenged by Stevens (1961), who has proposed that a power function describes better the stimulus-estimate relation, and that the exponent of this function is specific for each sensory modality. In the light of Stevens' power law, physiological findings are being reexamined and renewed comparisons made between data derived from recording electrical responses in the brain and those obtained from studies of subjective estimates of stimulus intensity. The purpose of the present study was to explore the stimulus-response relationship in evoked potentials recorded at thalamic and cortical levels of the visual pathway.

Methods. The experiments were conducted on nine cats and seven rabbits. Each animal was submitted to an operation under Nembutal, in which one pair of recording electrodes was implanted stereotaxically in the lateral geniculate body of one side and another pair ipsilaterally on the surface of the striate cortex. Distance between electrode tips was $1 \mathrm{~mm}$ in geniculate and 2.5 $\mathrm{mm}$ in cortex. The electrode assembly was attached to the skull with dental cement and the leads were soldered to a miniature plug for subsequent connection to recording equipment. Several days after recovery from the operation the animal was placed in a hammock with the head gently immobilized by means of a special holder. The pupils were maximally dilated by application of $2 \%$ atropine sulfate solution and $10 \mathrm{~min}$ of dark-adaptation were allowed to elapse before testing. A Grass photostimulator was used as the source of the stimulus, which was a sharp flash of about 10 $\mu \mathrm{sec}$ duration, providing an illuminance of approximately 0.9 $\mathrm{ft}-\mathrm{c} / \mathrm{sec}$ at the corneas. By means of neutral density filters this amount of illumination could be reduced to $85,70,55,40,30$, $15,7,4$, and $2 \%$ levels. Single flashes were presented at irregular intervals of 2-4 sec. Blocks of 15 flashes at each level of illuminance were given successively, first in descending and then in ascending order of illuminance. This provided a total of 30 test flashes at each level, including the maximum without filter. The electrical responses elicited in the geniculate body and in the cortex by every flash were amplified (time constant $=0.2 \mathrm{sec}$ ), displayed in pairs on the face of an oscilloscope, and photographed. Only changes in amplitude of the primary evoked potential are discussed in this paper; this potential occurs between 20 and $100 \mathrm{msec}$ after the flash. In the two locations the primary response recorded with bipolar electrodes takes the form of a diphasic wave, the peak-to-peak amplitude of which was measured in these experiments. Complete analysis was performed only on data from four cats and four rabbits which produced records generally free of artifacts and in which histology showed correct placement of the electrodes in the two selected recording sites.

Results. Throughout the range of light intensity utilized in this study the amplitude of geniculate and cortical evoked potentials was found to vary monotonically as a function of illuminance. Inspection of graphs on which the results from individual animals were plotted showed that both a logarithmic function and a power function could be used to describe reasonably well the stimulusamplitude relationship. In order to refine the analysis, the data were submitted to a special computer program of curve fitting by least squares method ${ }^{2}$ for the two functions:

and

$$
A=\mathbf{a} \log \mathbf{I}+\mathbf{b}
$$

$$
A=a^{n}+b,
$$

where A represents evoked potential amplitude, $I$ the level of illuminance, $a$ and $b$ are constants, and $n$ is the exponent of the power function. In both functions the additive parameter $b$ was used to account for the spontaneous potential fluctuations of the electroencephalogram. These potential fluctuations can be considered as background "noise" on which an evoked. response is superimposed.

Table 1 shows the variances obtained and the exponent of the power function per animal and electrode location. Because of considerable "trade-off" between the three parameters on fitting the power function, the estimate of $n$ was arrived at by introducing in the analysis values of amplitude at illuminance $O$, i.e., amplitude of background EEG. A comparison of the goodness of fit of the two functions can be made by treating statistically the ratio between the two respective residual variances (F-ratio). This procedure leads to uniformly nonsignificant ratios $(p>0.05)$, showing that in no case does one function provide a clearly better fit than the other. However, in the majority of instances the residual variance upon fitting the power function was somewhat smaller than that of the log function, whereby the general

Table 1

\begin{tabular}{|c|c|c|c|c|c|c|c|c|}
\hline \multirow[b]{3}{*}{ Animal } & \multicolumn{4}{|c|}{ LATERAL GENICULATE BODY } & \multicolumn{4}{|c|}{ VISUAL CORTEX } \\
\hline & \multirow[b]{2}{*}{$\begin{array}{c}\text { Total } \\
\text { Variance } \\
\end{array}$} & \multicolumn{2}{|c|}{ Residual Variance } & \multirow[b]{2}{*}{$\begin{array}{c}\text { Exponent } \\
\text { (n) }\end{array}$} & \multirow[b]{2}{*}{$\begin{array}{c}\text { Total } \\
\text { Variance }\end{array}$} & \multicolumn{2}{|c|}{ Residual Variance } & \multirow[b]{2}{*}{$\begin{array}{c}\text { Exponent } \\
\text { (n) }\end{array}$} \\
\hline & & $\begin{array}{c}\log \\
\text { Function }\end{array}$ & $\begin{array}{c}\begin{array}{c}\text { Power } \\
\text { Function }\end{array} \\
\end{array}$ & & & $\begin{array}{c}\text { Log } \\
\text { Function }\end{array}$ & $\begin{array}{c}\text { Power } \\
\text { Function }\end{array}$ & \\
\hline Cat No. 2 & 22.09 & 8.17 & 7.27 & .16 & 16.81 & 8.85 & 8.70 & .22 \\
\hline Cat No. 5 & 5.76 & 3.56 & 3.53 & .15 & 6.76 & 2.18 & 2.15 & .33 \\
\hline Cat No. 7 & 18.92 & 7.40 & 7.42 & .14 & 5.95 & 3.28 & 3.29 & .21 \\
\hline Cat No. 11 & 13.24 & 6.09 & 3.76 & .11 & 13.32 & 3.65 & 3.22 & .35 \\
\hline Rabbit No. 24 & 75.65 & 23.12 & 13.28 & .47 & 50.27 & 11.97 & 9.78 & .30 \\
\hline Rabbit No. 25 & 16.16 & 4.66 & 4.65 & .23 & 9.36 & 5.63 & 5.63 & .16 \\
\hline Rabbit No. 27 & 3.92 & 2.67 & 2.64 & .15 & 18.15 & 10.67 & 10.21 & .24 \\
\hline Rabbit No. 28 & 14.36 & 10.29 & 10.33 & .15 & 36.60 & 20.16 & 20.28 & .19 \\
\hline
\end{tabular}

Variances of Functions Tested and Exponents for Power Function 


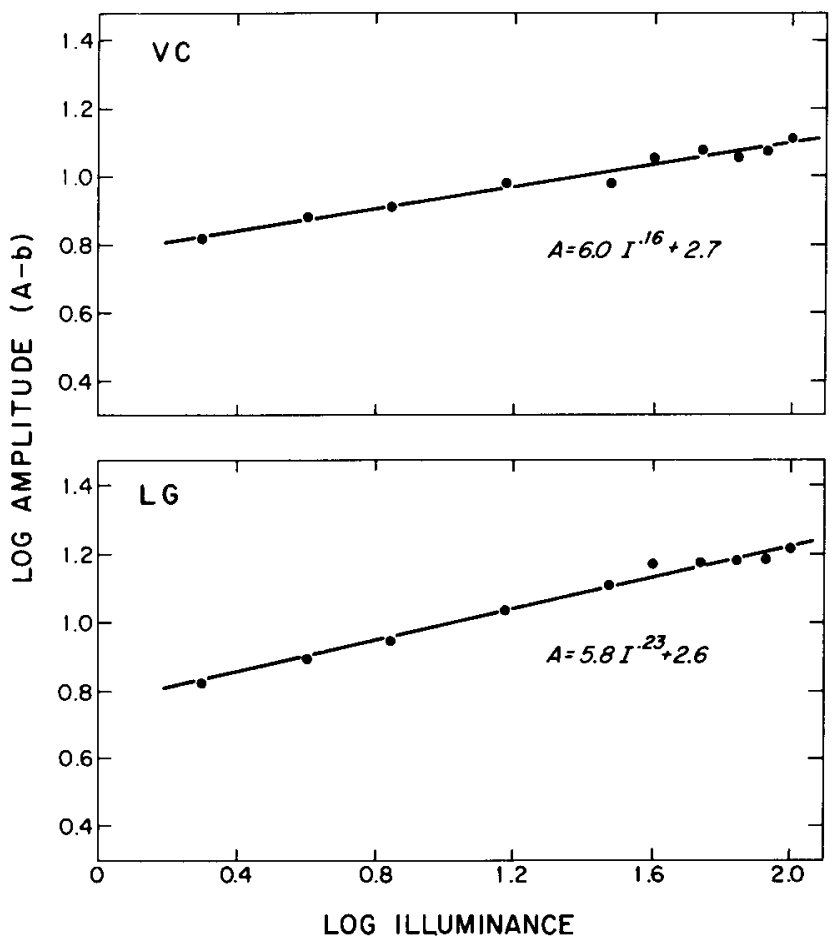

Fig. 1. Rabbit. Amplitude of evoked response in lateral geniculate body (LG) and visual cortex (VC) at different stimulus levels. Abscissa: $\log$ of relative illuminance in per cent. Ordinate: $\log$ of difference between amplitude of evoked response (A) and amplitude of background EEG (b) in arbitrary units. Line of best fit for power function as given in inset.

impression is obtained of a slightly better fit of the power function.

Figure 1 shows a graphic example of the stimulus-amplitude relation. The data are plotted with reference to log-log coordinates; using this form of representation the power function is characterized by a straight line, the slope of which is determined by the magnitude of the exponent. The exponents of the power function for the cats were found to be consistently higher in the cortex than in the geniculate body. Covariance of geniculate and cortical measures was generally observed, as may be expected from the physiological interdependence of the two structures. Joint fluctuations of values about the respective lines of best fit are one manifestation of this covariance.

Discussion. The two best known psychophysical functions are almost equally suitable to express the stimulus-response relation in measures of thalamic and cortical visually evoked potentials. These results, as those of investigations which have previously dealt with the same question in other sensory systems (review by Rosner \& Goff, 1967) point to the difficulty in attempting to attribute to either function the character of a general principle. It is noteworthy that here, as well as in other studies in which a power function has been shown applicable to the visual system, whether on dealing with unit reactions (Fuster et al, 1965; Straschill, 1966) or evoked potentials (Vaughan \& Hull, 1965), the exponent found for the function is usually quite low, of a value comparable to that obtained by Stevens (1961) for psychophysical estimates of brightness $(0.33)$ or even lower. This author has remarked that the exponents for vision and audition are very low possibly because the sensory transducers for light and sound act as "compressors" and are thus capable of handling very wide ranges of stimulation. Differences between exponents for geniculate and cortical responses, such as are seen in some of our results, may indicate a nonlinear transformation of geniculate output to the cortex. The concept of successive nonlinear transformations of information along a sensory pathway has been considered by some investigators. With respect to the visual system, MacKay (1963) has demonstrated that a neural process of matching peripheral input with internally generated activity could make a power function at central level compatible with a log function at the receptor level.

\section{REFERENCES}

FUSTER, J. M., CREUTZFELDT, O. D., \& STRASCHILL, K. Intracellular recording of neuronal activity in the visual system. $Z$. vergl Physiol, 1965 , 49, 605-622.

GRANIT, R. Receptors and sensory perception. New Haven: Yale University Press, 1955.

HARTLINE, H. K., \& GRAHAM, C. H. Nerve impulses from single receptors in the eye. J. cell comp. Physiol., 1932, 1, 277-295.

MacKAY, D. M. Psychophysics of perceived intensity: a theoretical basis for Fechner's and Stevens' laws. Science, 1963, 139, 1213-1216.

ROSNER, B. S., \& GOFF, W. R. Electrical responses of the nervous system and subjective scales of intensity. In W. D. Neff (Ed.), Contributions to sensory physiology. New York: Academic Press, 1967. Pp. 169-221.

STEVENS, S. S. The psychophysics of sensory function. In W. A. Rosenblith (Ed.), Sensory communication. Cambridge: Technology Press, 1961. Pp. 1-13.

STRASCHILL, M. Aktivität von Neuronen im Tractus opticus und Corpus geniculatum laterale bei langdauernden Lichtreizen Verschiedener Intensität. Kybernetik, 1966, 3, 1-8.

VAUGHAN, H. G., \& HULL, R. C. Functional relation between stimulus intensity and photically evoked cerebral responses in man. Nature, 1965 , 206, 720-722.

\section{NOTES}

1. This research was supported by Grants NB 04133 and K3-MH-25,082 from the U.S. Public Health Service.

2. The operation was performed by an IBM $360 / 75$ computer; the program is designated as BMDX 85 and its description is available from the Health Sciences Computing Facility, University of California, Los Angeles. 